\title{
On the Sedimentary Structure in Some Portions of the Pacific Ocean from data on Seismic Reflected Waves $\left(^{*}\right)$
}

\author{
S. M. ZVEREV
}

Ricevuto il 7 dicembre 1960 .

1. During 1957-1958 the Institute for Physics of the Earth of the Ac. Sci. USSR carried out investigations by deep seismic sounding (DSS) of the earth's crust in the north-western part of the Pacific ocean and in the adjoining aquatoria $\left({ }^{1,2}\right)$. The investigation technique consisted mainly in following on the seismograms the seismic waves coming from the deep boundaries in the crust. At the same time data were also collected on the structure of the upper layer consisting of ocean sediments.

2. Simultaneously with the seismic waves coming from the deep crustal layers, vertical reflections from the bottom surface and from the boundaries in the sediments were also observed in order to investigate the structure of the sediments. The observations of the reflected waves were carried out by two methods.

When heavy charges (above $100 \mathrm{kgr}$ ) were fired for I)SS observations, a unichannel set on the moving ship was used for recording reflected waves. A piezocrystal secured to the underwater part of the ship's hull served as a receiver. The preamplified signal was recorded in a wide frequency range and then passed through a narrow band-pass filter. The frequency band was so chosen as to increase the effective sensitivity of the channel. It was known from experience that good records of reflected waves were obtained in the $50-70 \mathrm{c} / \mathrm{sec}$ frequency range. A sample seismogram is shown in fig. 1 . On this and similar seismograms not only reflections from subbottom boundaries are seen, but also pulses due to secondary shocks and possibly also to reflections from the water surface at the shooting point.

(*) Paper read at the Helsinky Assembly of the I.U.G.G. 1960. 
By this method reliable records of waves reflected from boundaries in the sediments were obtained at ocean depths of 5-6 km. In the region of the deep-water through the intensity of the reflected waves decreased and this method proved not sensitive enough to produce reliable records.

The conditions for firing the charges and for reception were sufficiently uniform, so that we were able to compare the behaviour of the reflecting boundaries over large areas.

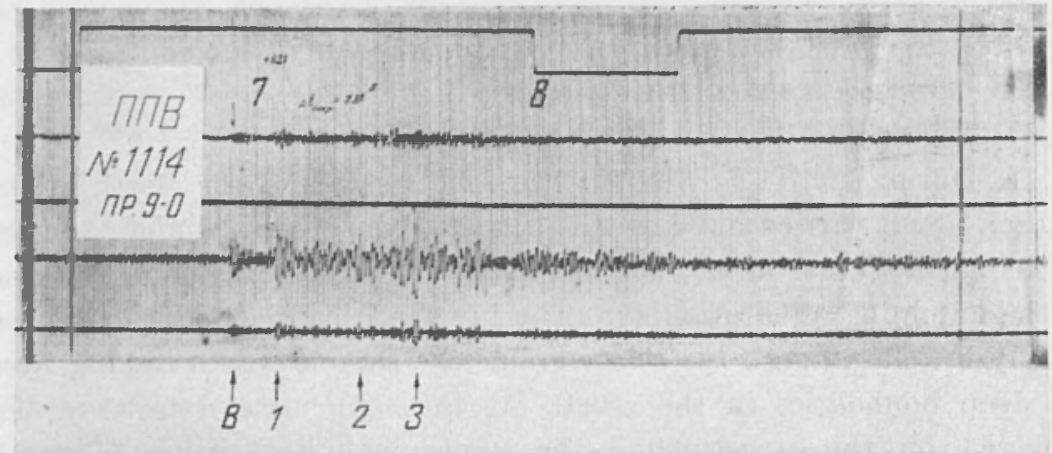

Fig. 1 - A sample record of waves reflected from the bottom surface (B) and from the boundaries in the sediments $(1,2,3)$, obtained on the moving ship. Traces 4 and 5 at the top are records of differently amplified signals.

3. During the short stops of the moving ship recording was made on a floating multichannel set similar to those used in prospecting for oil. In the observations of 1958 a set consisting of six hydrophones distanced at 50 metres was used. Their stretching into line was left to the ship's wind drift. The seismic observations of the reflected waves were carried out simultaneously with oceanologic observations. Charges of 1-5 kgr suspended on rubber floats were used. The amplifiers chosen were similar to those used in prospecting. Reflected waves having frequencies of $30-35 \mathrm{c} / \mathrm{sec}$ were recorded. A sample seismogram is given in fig. 2 . Since our reciever contained no volume control nor mixer, we were able to make use of the dynamic characteristics of the records.

Because of different ways in which the charges were fired and records made, the absolute times of arrival of waves reflected from the same boundary obtained from both sets differed considerably. After corrections had been introduced for the movement of the ship and for 

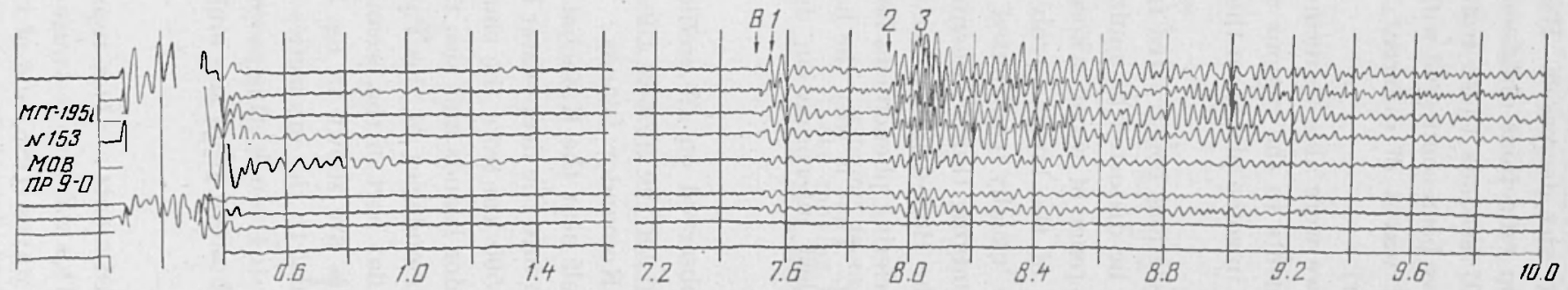

Fig. 2 - A sample record of reflections from the bottom (B) and from the boundaries in the sediments (1,2,3) obtained on the multichannel set. Traces $1-5$ at the top - are records from different hydrophones. Traces 6-9 represent, records from the 1-t, 3-d and 5-th hydrophons having a lower sensitivity. 
different shooting depths this difference decreased. However, even then the times of arrival of the bottom reflections obtained from the multichannel set exceeded by 0,01-0,07 seconds those from the records by the unichannel set. This might have been connected with different depths of penetration into sediments of waves of different frequencies (lowfrequency waves penetrate deeper).

Using the multichannel set, we were able to record waves reflected from the boundaries in the sediments in the regions of the ocean bed, of the deep-water trough and also in some places on the shelf.

5. It should be noticed that sections constructed from experimental dirta on vertical reflections might be distorted by multiple reflections of waves in crustal layers, by interference of waves whose wavelengths are comensurable with the thickness of the layers involved and by other complicating phenomena we are usually confronted with in seismic prospecting. In our case when studying thin sedimentary layers underlying a deep water layer, with the time-distance curves extending not far enough, discrimination of interfering phenomena becomes even more difficult than in usual prospecting. That is why the here given sections should be considered as a simplest interpretation depicting to some extent the real situation.

6. Vertical reflections were observed on all profiles made in 1958. Iset us consider the data obtained on the profiles running close to the Kamchatka peninsula and the Komandor islands Profiles NoNo 7 and 9 crossing the continental shelf near the Kamchatka peninsula and the Kurile-Kamchatka trough, ran into the deep-water bed of the Pacific ocean extending at a distance of $500 \mathrm{~km}$ from the shore. Profile No 8 crossed the shelf near the Komandor islands and also the Aleutian deepwater trough, ending within the boundaries of the Pacific border swell at a distance of $150 \mathrm{~km}$ from the flat part of the ocean bed.

Sections through these profiles are shown in fig. $3,4,5$. The thin lines whose lengths are proportional to the intensities of the reflections taken from the seismograms illustrate the reflecting power of the boundary under consideration. The data obtained from the multichannel set are marked out.

7. The sections through the sediments are here represented in times of arrival instead of in thickness. This was done because with the methors used for observations of refracted waves (DSS) and of vertical reflections 


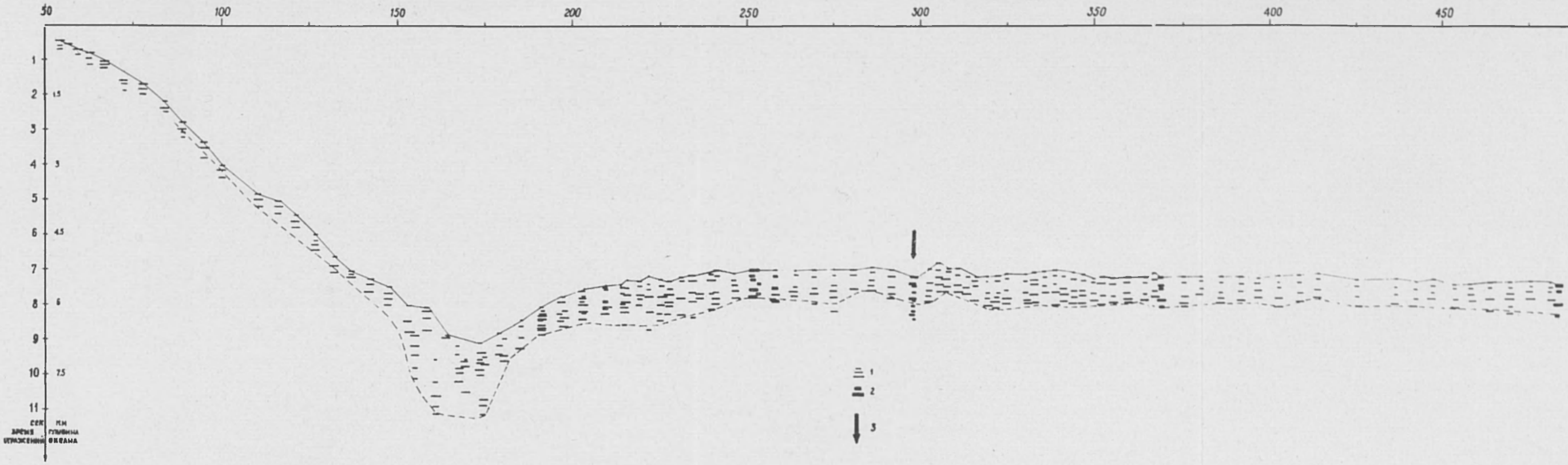

Fig. 3 - Times of arrival of vertical reflections on profile No 9 crossing the Kurile-Kamchatka deep-water trough beginning from the southern extremity of the Kamclatka peninsula. 1) times of arrival obtained from observations of reflections made on the moving slip; 2) times of arrival obtained from the multichannel set; 3) places on the profile where a sharp change in the times of arrival of reflections from the bottom and from the boundaries in the sediments was observed.

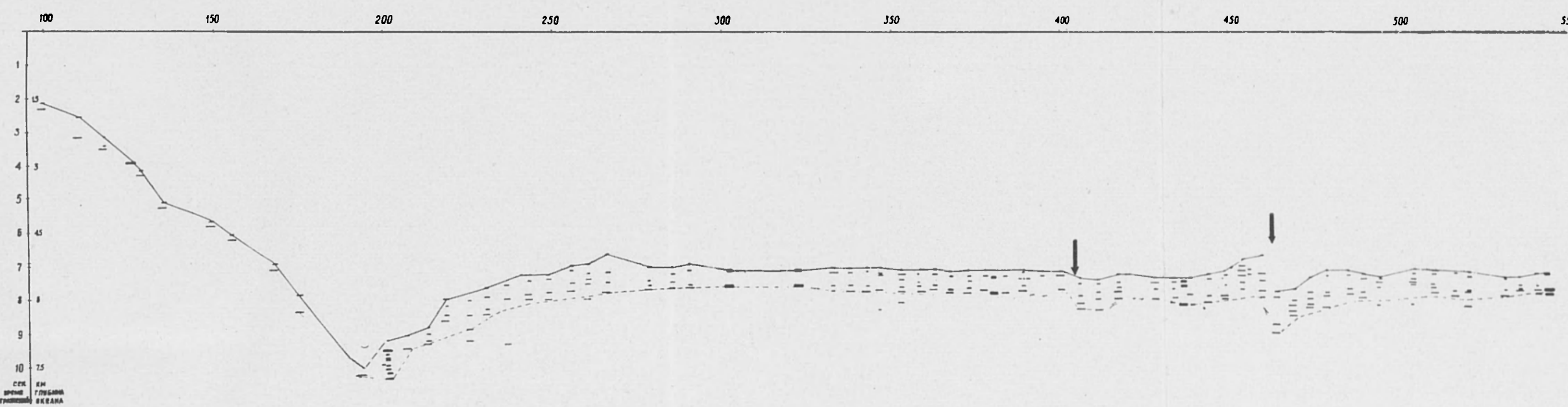

Fig. 4 - Times of arrival of vertical reflections obtained on profile No 7 crossing the Kurile-Kamchatka deep-water trouglı from the region of Petropavlovsk-Kamchatski. Designations the same as in fig. 3. 
the determination of velocities in the sediments becomes extremely difficult. Although some data on the velocities were obtained, this problem cannot be considered as finally solved. However, the here given data can be used for a comparative geologic interpretation. Moreover, the velocity range in the sediments might be indicated and the thickness of separate layers roughly calculated.

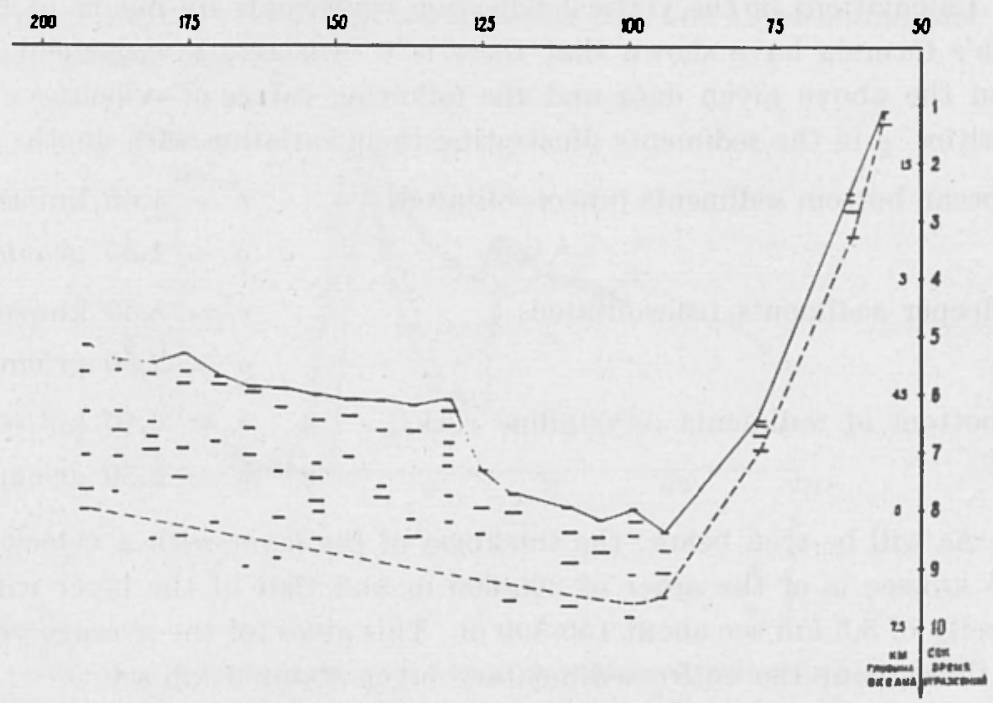

Figr. 5 - Times of arrival of vertical reflections on profile No 8 crossing the Aleutian deep-water trough from the Komador islands.

8. In evaluating the velocities in the sediments use was made of the multiple reflections in the water layer picked out from the DSS seismograms and also of the reflection coefficient calculated from different vertical reflections. From an analysis of the multiply reflected water waves, including the regions of growing amplitudes connected with the critical angles $\left({ }^{3}\right)$, on one of the profiles considered below running above the ocean bed, the following values of velocities were obtained: in the subbottom layer - 1,62-1,67 km/sec $\left(^{*}\right)$ and in the deeper layer $1,89-1,91 \mathrm{~km} / \mathrm{sec}$. The way in which the experimental data agree with

(*) Here and below the thin layer (5-14 $\mathrm{m}$ thick) covering the sea bottom is not taken into consideration. Weak reflections froms this layer can be seen on the seismograms of fig. 2 . 
theory (fig. 6) gives reasons to consider the velocity $1,89-1,91 \mathrm{~km} / \mathrm{sec}$ as belonging to transversal waves. If so, then the velocity of the longitudinal waves in the deeper layer becomes $3,2-3,5 \mathrm{~km} / \mathrm{sec}$.

From the relation between the amplitudes of the first and double vertical reflections the following average reflection coefficients were obtained: for the bottom surface $-0,17$; for the sharpest boundary 0,58 and for the deepest reflecting boundary $-0,34$.

Calculations of the vertical reflection coefficients by means of Rayleigh's formula have shown that there is a satisfactory agreement between the above given data and the following values of velocities $v$ and densities $o$ in the sediments illustrating their variation with depth:

a) ocean bottom sediments (unconsolitated)

$$
\begin{aligned}
& v=1,65 \mathrm{~km} / \mathrm{sec} \\
& \bar{\varrho}=1,35 \mathrm{gr} / \mathrm{cm}^{3} \\
& v=3,50 \mathrm{~km} / \mathrm{sec} \\
& \underline{o}=2,50 \mathrm{gr} / \mathrm{cm}^{3} \\
& v=6,40 \mathrm{~km} / \mathrm{sec} \\
& \underline{\varrho}=2,80 \mathrm{gr} / \mathrm{cm}^{3}
\end{aligned}
$$

As will be seen below, the thickness of the layer with a velocity of $1,65 \mathrm{~km} / \mathrm{sec}$ is of the order of $300-600 \mathrm{~m}$ and that of the layer with a velocity of $3,5 \mathrm{~km} / \mathrm{sec}$ about $150-300 \mathrm{~m}$. This gives for the average velocity throughout the entire sedimentary layer about $2 \mathrm{~km} / \mathrm{sec}$.

All the above given velocities are very approximately estimated. It should be noticed though, that all the obtained data are not yet used and in particular, the existence of a thin layer of consolidated sediments having a velocity of $3,5 \mathrm{~km} / \mathrm{sec}$ should not be considered as finally proved.

Further investigations are needed to determine more accurately the distribution of velocities in the sediments.

9. We shall now consider the sections through the profiles made. On all three of them a sharp change in the nature of sediments is observed when crossing the deepwater trough. On the eastern slope of the trough a distinct and relatively stable layering of the sediments is observed for long stretches of the profile. The amplitude of the bottom reflection is usually 2-4 times smaller than that of the later reflections. This indicates that the sea bottom is a less sharp boundary than the deeper boundaries in the sediments. On the west slope of the trough facing the land the layering of the sediments is less obvious. The reflect- 
ing power of the sea bottom is very variable and on the whole 2-3 times larger that of the ocean bed region. This means high densities and velocities of the rocks of the sea bottom whose composition is rapidly carying.

10. On profile No 9 running to south-east of the southern extremity of the Kamchatka peninsula, on the western slope of the deep-water trough 3 reflecting boundaries were observed. The difference in times of arrival $(\Delta t)$ of waves reflected from the first and third boundaries was 0,2-04, second (fig. 3).

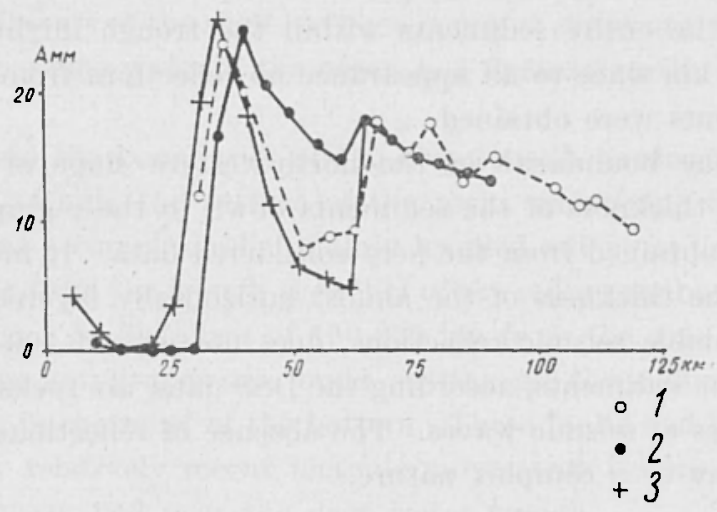

Fig. 6 - A comparison of experimental and calculated amplitude curves for water waves thrice reflected in the ocean having for an object the determination of velocities in the sediments:

1) experimental data; 2) data calculated for the first critical angle (the second maximum in the curve corresponds to a velocity of $1,65 \mathrm{~km} / \mathrm{sec}$ in the subbottom layer; and the first maximum - to the velocity $1,90 \mathrm{~km} / \mathrm{sec}$ of longitudinal waves in the deeper sedimentary layer; (3) data calculated for the second critical angle (the first maximum corresponds to a velocity $1,90 \mathrm{~km} / \mathrm{sec}$ of the transversal waves in the deep sedimentary layer).

In the region of the deep-water trough 5-6 reflecting boundaries were found, $\Delta t$ between successive arrivals having been $1,5-1,8$ seconds.

Within the boundaries of the oceanic swell, bordering the southeastern slope of the deep-water trough, 2-5 reflecting boundaries were observed. Near the trough $\Delta t$ varied considerably from 0,2 to 0,9 seconds thus indicating a complex relief of the surface underlying the sediments. At a distance of $130 \mathrm{~km}$ from the axis of the trough a sharp change in the 
relief of the bottom and a displacement of the reflecting elements was found indicating a faulted surface of the rocks underlying the sediments. At longer distances from the axis of the trough 3-4 reflecting boundaries were detected. With moving away farther from the axis the relief of the reflecting surface became more uniform and the time interval between successive reflections decreased, reaching 0,4-0,7 seconds. Assuming and average velocity in the sediments of $2 \mathrm{~km} / \mathrm{sec}$ we obtain the following values for the thickness of the layered sediments: in the region of the trough $-1,5-1,8 \mathrm{~km}$; in the ocean bed elose to the trough - 0,2$0,9 \mathrm{~km}$ : along the south-eastern part of the profile $-0,4-0,7 \mathrm{~km}$. The thickness of the entire sediments within the trough might have been larger than $2 \mathrm{~km}$ since to all appearance no reflections from the bottom of the sediments were obtained.

Within the boundaries of the north-western slope of the trough the summary thickness of the sediments down to the "granitic" layer could not be obtained from the here considered data. It might be only stated that the thickness of the almost horizontally layered sediments, giving appreciable seismic reflections, does not exceed 100-300 metres. Underlying the sediments, according the DSS data, are rocks also having small velocities of seismic waves. The absence of reflections shows that these rocks are of a complex nature.

11. The section through profile No 7 (fig. 4) is basically similar to that of profile No 9 . The relief is more uniform and sediments are found near the south-eastern slope of the trough. Here $\Delta t$ varies between 0,5 and 0,9 second (and the thickness from 0,5 to $0,9 \mathrm{~km}$ ). At a distance of $250 \mathrm{~km}$ from the axis of the trough a fault was detected cutting all the sedimentary layers and appearing in the relief as a ledge with an amplitude of about $800 \mathrm{~m}$. A fault of a smaller amplitude was found at a distance of $200 \mathrm{~km}$ from the axis of the trough. At the south-eastern end of the profile the thickness of the sediments was $0,4-0,7 \mathrm{~km}$.

12. Let us discuss now the data obtained on the profile running south-west of the Komandor islands through the aleutian trough (fig. 5). These data are less reliable because of bad weather which prevented us from using the multichannel set.

On the side facing the shelf $2-4$ reflecting boundaries were found corresponding to $\Delta t$ not exceeding 0,5 second. In the region of the trough and to the south of it the number of reflecting boundaries increased sharply reaching 8 and even more. The time interval $\Delta t$ between successive 
reflections was 2.0-2,5 seconds, i.e. 2-3 times those observed in the ocean bed on profiles NoNo 7 and 9 . From these figures follows that in the region of the Pacific ocean border swell near the Aleutian trough the thickness of the sediments was no less than $2,0-2,5 \mathrm{~km}$.

\section{ConClusions.}

1. The deep water trough divides the horizontally layened sediments of the ocean bed only, relatively slightly varying in thickness, from the variable sediments of the shelf having a complex structure. The thickness of the sedimentary rocks of the ocean bed decreases with distance from the trough.

2. Within the boundaries of the ocean swell, bordering the KurileKamchatka trough, the surface of the rocks underlying the ocean bed sediments has a complex relief mainly levelled out by sediments. When moving away from the trough the relief of the sediments bottom becomes more uniform. At distances of $150-250 \mathrm{~km}$ from the axis of the trough faults of large amplitudes are found cutting all the sedimentary layers and showing in the relief of the bottom. These faults had been probably produced by relatively recent tectonic movements occuring on the border of the ocean bed near the deep-water trough.

3. Within the boundaries of the Pacific border swell near the Aleutian deep-water trough, the thickness of the sediments is $2-3$ times that of the sediments in the ocean bed, close to the Kurile-Kamchatka trough. This indicates that the conditions for accumulation of sediments in the outer parts of the Kurile-Kamchatka and of the Aleutian deep-water troughs are essentially different.

\section{$S U M M A R Y$}

The special observation of vertical reflected waves, made during the I GY simultaneously with deep seismic sounding in the Pacific Ocean, allowed to study the structures of sediments, covered the ocean bed near Kurilo-Kamchatka and Aleutian trenches. The profiles of observations crossed some great faults, disturbing sedimentary complex on the whole its depth. 


\section{SOMMARIO}

La particolare osservazione delle onde verticali riflesse, effettuata durante l'A.G.I., contemporaneamente al sondaggio sismico profondo nell'oceano Pacifico, ha permesso di studiare le strutture dei sedimenti, ricoperte dal fondo dell'Oeeano presso Kurilo-Kamchatka e le trincee Aleutine. I profili delle osservazioni hanno incontrato alcune grosse faglie, che disturbano il complesso sedimentario in tutta la sua profondita.

\section{REFERENCES}

(1) Galperin, E. I., Goruachev A. V., Zverev S. M., Investigation of the earth's crust in the zone of transition from the Asiatic continent to the Pacific ocean. Publ. House of Ac. Sci. USSR, M. (1958).

(2) VASILOEV V. G. and oth., Investigation of the earth's crust in the zone of transition from the Asiatic continent to the Pacific ocean. Symp. "Soismic investigations during the IGY " 4, Publ. House of Ac. Sci. USSR, (1960).

(') ZVEREv S. M., Multiply reflected water waves and their use for the determinaion of velocities in the sediments. Trans. Ac. Sci. USSR, geoph. ser. 1. (1960). 